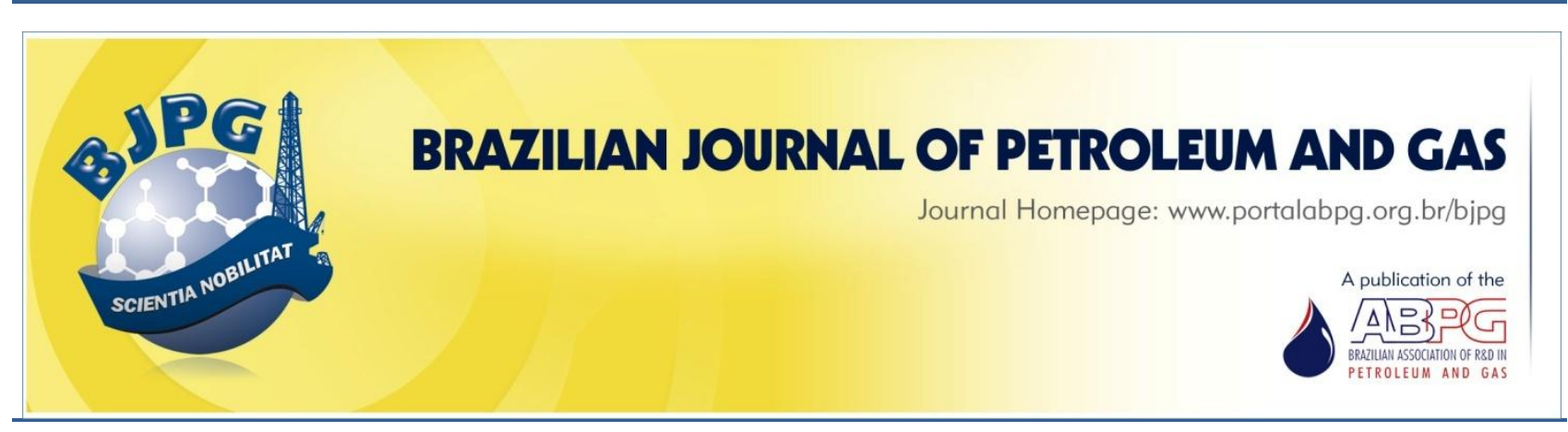

\title{
CASE STUDY: ECONOMIC AND TECHNICAL ANALYSIS OF RETROGRADE GAS PROCESSING ON OFFSHORE PLATFORMS
}

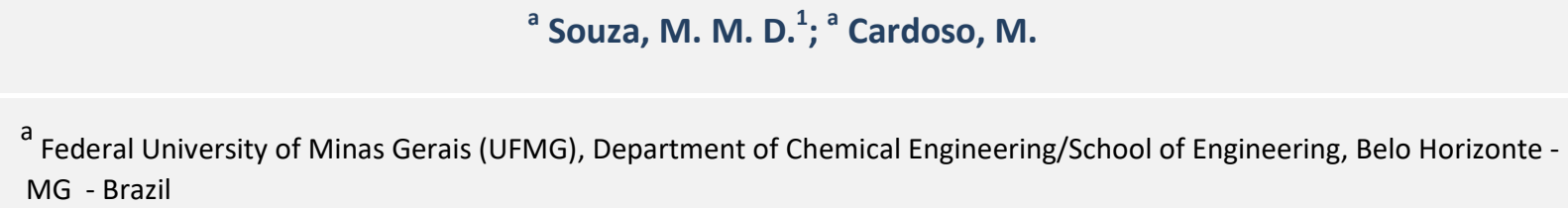

Received: 22.10.2018 / Accepted: 25.11.2018 / Published on line: 10.01.2019

\begin{abstract}
Recent discoveries of retrograde gas fields in Brazilian deepwaters are more distant from the shore, and away from available infrastructure for processing gas. In this scenario, processing the gas offshore becomes an important challenge, equipping these fields to become viable producers. The present study aims to evaluate the economic motivation for this concept by comparing two scenarios of retrograde gas production. The scenarios consider processing the gas to sales based on: 1. Production offshore and gas export to a new built onshore processing plant, and 2. Production and treatment of the gas offshore. The second scenario considered three hydrocarbon dew point treatments: Joule-Thomson, Turboexpansion, and Refrigeration. The economic assessment used the software QUE\$TOR ${ }^{\circledR}$. Following the assessment, process simulations used ASPEN HYSYS ${ }^{\circledR}$ to perform the technical evaluation. The economic results were promising despite connected strongly to gas price. The simulation results indicated that the use of dew point treatments are viable but depend on feed gas composition.
\end{abstract}

\section{KEYWORDS}

retrograde gas; natural gas; oil and gas; gas processing; gas processing offshore

\footnotetext{
${ }^{1}$ To whom all correspondence should be addressed. Address: Federal University of Minas Gerais (UFMG), Department of Chemical Engineering/School of Engineering, Av. Antônio Carlos 6627, Pampulha, Belo Horizonte, Brazil. ZIP Code: 30160-030 | e-mail: marina.maciel3@gmail.com doi:10.5419/bjpg2018-0021
} 


\section{INTRODUCTION}

Due to environmental concerns, a growing interest for natural gas is prompting the search for fuels with clean burning and lower carbon dioxide emission (Lee et al., 2012). Such interest led to a worldwide geographic expansion of gas reserves with new developments. In this scenario, there is a growing interest to monetize midscale (14-140 billion cubic meters) and small-scale gas reserves (Lee et al., 2015). However, most of the world's gas reserves are in offshore fields (Lee et al., 2012) at ultra-deep waters. These offshore fields lack adequate infrastructure and are distant from consumers (Lee et al., 2013), deeming mid and small-scale non-associated gas reserves stranded (Dickson et al., 2015).

The infrastructure required to develop offshore gas fields usually comprises a subsea system, an offshore platform (for separation, contaminants and water removal, and compression), pipelines to shore, an onshore gas processing plant and pipelines for sales gas distribution (Lee et al., 2012). The use of the entire system is necessary to separate and process the natural gas, whether associated gas or retrograde gas. Unlike it, dry gas may not require some of these facilities to comply with the sales gas specifications established by the Brazilian National Agency of Petroleum, Natural Gas and Biofuels- ANP (Agência Nacional de Petróleo, Gás Natural e Biocombustíveis). ANP's Resolution N. 16, of 2008, regulates the transportation, sales and consumption of gas (ANP, 2008). Consequently, the development of gas projects requires high investments, especially considering that gas revenues are usually lower than that of oil fields. Gas has a lower price when compared to the heavier hydrocarbon products from oil fields making it harder to develop a profitable isolated retrograde gas field. This difference has a stronger impact on the costs of non-associated gas field projects depending on the gas composition, the water depth, distance to shore and availability of processing infrastructure onshore. Since a new onshore infrastructure can represent a high investment, the possibility of processing the gas offshore could make a retrograde gas field considered stranded become profitable (Souza et al, 2016).

The objective of the present work is to evaluate economically and technically the feasibility of introducing additional systems for processing gas to sales offshore. It compares this alternative to the standard option of treating the gas offshore and processing to sales onshore for a nonassociated retrograde gas field case study. The economic comparison used the cost estimate software QUE\$TOR ${ }^{\circledR}$. Process simulator Aspen HYSYS $^{\circledR}$ assessed the technical feasibility of the process. It considered three processes similar to those used in onshore processing units for dew point adjustments, such as Joule-Thomson valve, turboexpansion, and refrigeration cycle.

\section{BACKGROUND}

Reservoir fluids are classified into five main groups, namely: dry gas, wet gas, retrograde gas or gas condensate, volatile oil and black oil (Rocha, 2014). Gas condensate is composed mainly of methane, such as dry and wet gas, but has a higher molecular mass due to the fractions of heavy hydrocarbons. Gas condensate fluid is a singlephased gas in the reservoir at exploration time, but with the pressure reductions from the production, a condensation into the liquid phase occurs and gas and condensate forms. Retrograde gas reservoirs have a higher value than dry and wet gases due to the condensate, which has valuable intermediate hydrocarbons, but at a lower amount than oil reservoirs (Alcheikhamdon \& Hoorfar, 2016). At the same time, these types of reservoir require more processing of the gas to achieve the sales specifications than dry and wet gases and, therefore, more processing investments are necessary.

For a field distant to shore and under ultradeep waters, there are many high investments to consider, such as the purchase of long pipelines, subsea high-pressure equipment and onshore processing infrastructure. The latter may represent a high percentage of the cost for production development projects in a new area. In addition, risks and difficulties with environmental licensing may occur in case the onshore plant would be located in a Green Field area. If this investment could be minimized with the use of gas processing technologies offshore, this would represent a big financial upside, mitigating risks and reducing expenses associated to the construction of big installations onshore, such as obtaining environmental licensing (Souza et al, 2016). 


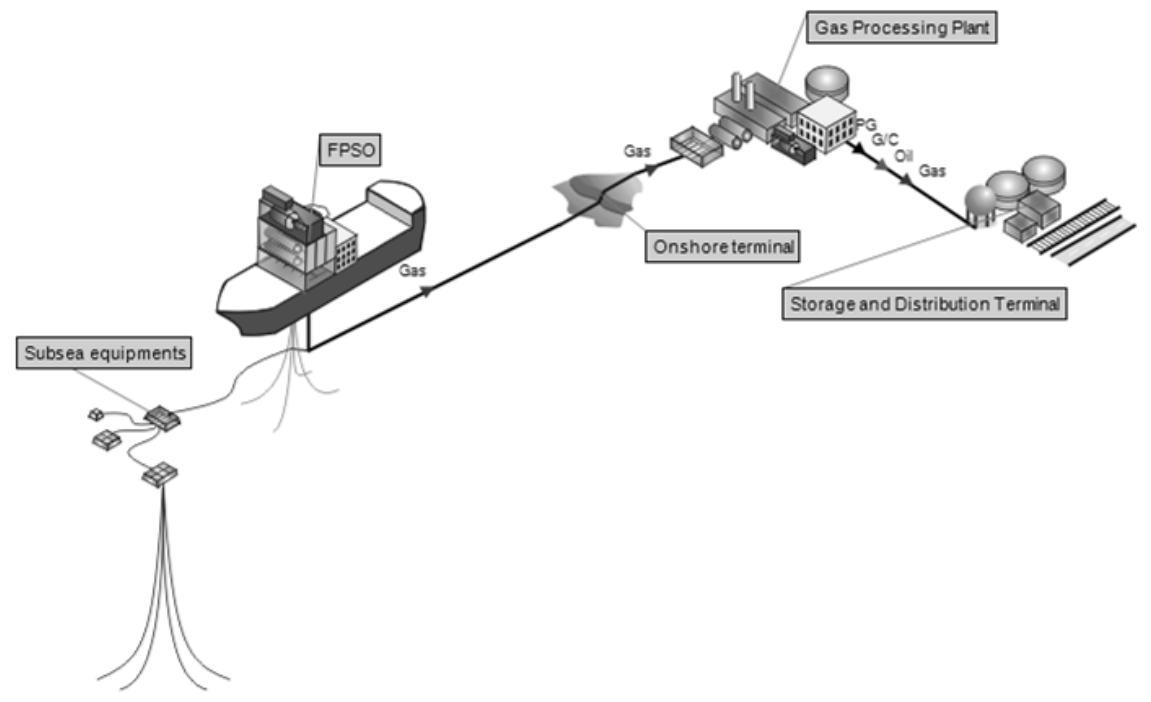

Figure 1. Production concept scheme of a retrograde gas field with gas export to an onshore processing plant.

Deciding between offshore and onshore processing of gas is obvious in most of the developed offshore regions of the world for it is usually defined by the existence of available infrastructure such as pipeline systems and onshore reception and processing facilities (Bothamley, 2004). Most of the offshore platforms only dehydrate and send the gas to be processed onshore. It is relatively rare to produce offshore stabilized crude and specified gas. This is because of the difficulty associated to handling intermediate components, such as butane and pentane, which tend to get "caught" between the crude product vapor pressure specification and the hydrocarbon dew point of the gas, along with the additional topsides costs and complexity (Bothamley, 2004). When processing onshore, the main objective is to maximize the production of higher value products such as ethane, propane, and butane. When processing offshore, the main objective is to specify both condensate or oil and gas without any intermediate stream. The composition of the fluid entering the unit is very important to assess the feasibility of the operation. The processes are different when the gas contains acid gases. Also, for some fluids, the processes may generate such a high stream of intermediate hydrocarbons that cannot be incorporated in neither of the product streams and may build up in the system. Therefore, it is important to evaluate both economic and technical feasibility of this concept in early development phases of the field project for each retrograde gas.

\section{CASE STUDY}

For the comparison between the gas processing onshore and offshore, this study considered the parameters of what could represent a stranded retrograde gas field of medium-size reserve in offshore Brazilian waters. The parameters are as follows: reservoir at 2,500 meters water depth producing a $43{ }^{\circ} \mathrm{API}$ stabilized condensate, a gas with $23.6 \mathrm{~kg} / \mathrm{kgmol}$, a CGR of $4,000 \mathrm{Sm}^{3} / \mathrm{Sm}^{3}$, fluid with a maximum amount of $0.5 \% \mathrm{CO}_{2}$ and no $\mathrm{H}_{2} \mathrm{~S}$. This study did not consider, at this stage, the presence of acid gas since this would require more processing offshore. The analysis was performed considering 100, 200, and 300 kilometers of distance to shore.

For the capital expenditure (CAPEX) estimates, a Floating Production Storage and Offloading (FPSO) vessel was designed for the following maximum capacities: $8.5 \times 106 \mathrm{Sm}^{3} / \mathrm{d}$ of gas, $9,000 \mathrm{Sm}^{3} / \mathrm{d}$ of condensate, and $50 \mathrm{Sm}^{3} / \mathrm{d}$ of produced water producing for 20 years. These parameters should represent any ultradeep water retrograde gas field in the Brazilian coast with similar production capacities of the pre salt platforms.

Two scenarios evaluated the economic advantages of the concept of an offshore gas processing unit. Scenario 1 comprised the standard production of dehydrated gas and stabilized condensate offshore in a FPSO, with gas being exported to an onshore gas plant (Figure 1). This 


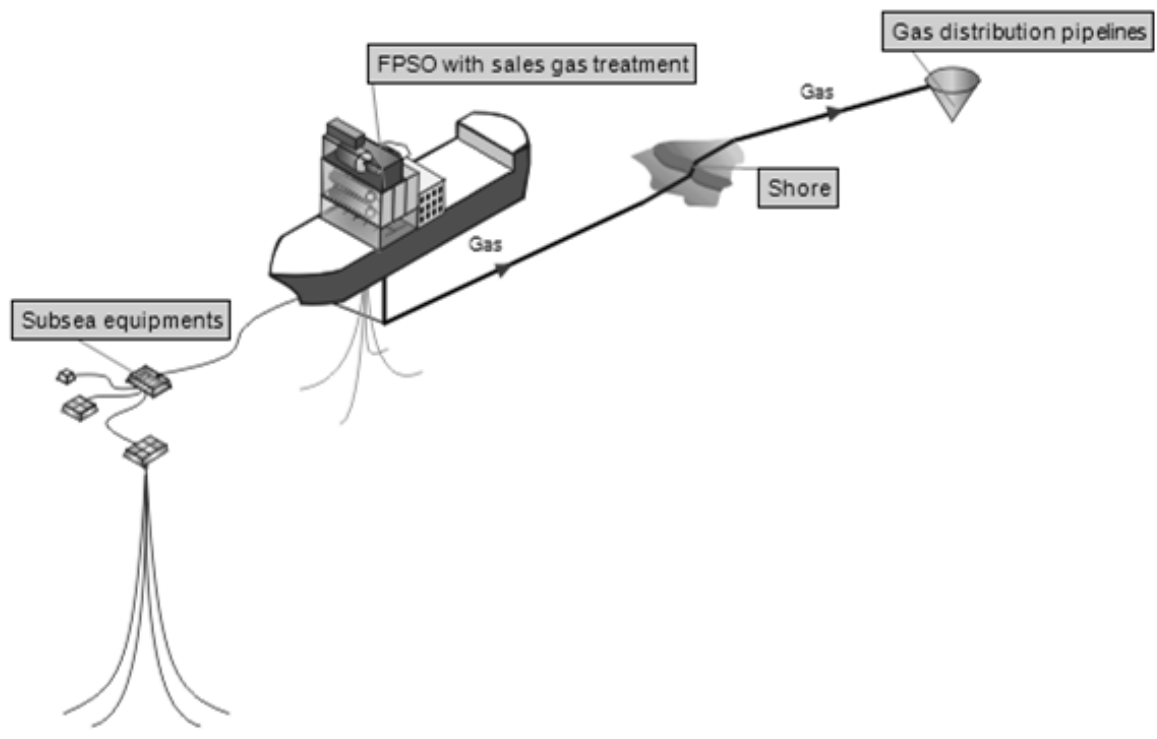

Figure 2. Production concept scheme of a retrograde gas field with gas processing to sales offshore.

option considered the production of higher profitable sales gas and also liquid natural gases, such as liquefied petroleum gas (LPG) and nafta. Scenario 2 comprised the production of sales gas using Joule-Thomson (JT), turboexpansion, or refrigeration for the dew point adjustment. It also produced stabilized condensate offshore in a FPSO and considered the export of sales gas directly to an onshore distribution pipeline (Figure 2). The present paper aims at comparing the scenarios economically, since the economic motivation is more uncertain than the capability of the three gas processes to produce gas within specifications, for they are largely used in the NGL recovery.

\section{METHODOLOGY}

\subsection{Economic evaluation}

The economic evaluation used software QUE\$TOR $^{\circledR}$, version 2016 Q3, to estimate the capital (CAPEX) or investment costs, and operational (OPEX) costs of offshore and onshore facilities and a production curve. This version of the software, developed by IHS Energy Corporation, has an updated database specific for the Oil and Gas industry. Many authors used this software to support their project evaluation (Lu et al. (2006), Attanasi \& Freeman (2010), and Yananto \& Girindra (2016)). All the assessments used the same economic model and relative index for comparison. Therefore, the present evaluation focuses mainly on the comparison rather than the actual calculated costs. The economic parameters evaluated and compared for both scenarios were:

$\checkmark$ Net Present Value (NPV) considering the incomes and expenses during the project's lifecycle;

$\checkmark$ Internal Rate of Return (IRR) which is the rate at which the NPV equals to zero and should be compared to the hurdle rate considered (Lion et al., 2014);

$\checkmark$ Return on Investments (ROI), which represents the ratio between the NPV and the CAPEX (Yang et al., 2016). The ROI is very useful to prioritize projects when the capital is limited (Tang et al., 2017).

In this study, the average brent oil of US\$ 55 per barrel was used to estimate the condensate revenue, US\$ 300 per metric ton for the liquefied petroleum gas and US\$ 58 per barrel of gasoline considering the Brazilian market (IHS Markit, 2017). It considered a price of US\$ 6.00 per million BTU as a mean value informed by Petrobras (Petrobras, 2017). The hurdle rate considered was $11 \%$, which corresponds to the average Brazilian Selic base interest rate. Following the evaluation and comparison of both scenarios, a sensitivity analysis evaluated the impact of price variations of 
Table 1. Chemical composition of reservoir fluid entering the platform.

\begin{tabular}{cccc}
\hline & Rich gas & Medium gas & Poor gas \\
\hline $\mathbf{H}_{\mathbf{2}} \mathbf{S}$ & 0.0000 & 0.0000 & 0.0000 \\
$\mathbf{C O}_{\mathbf{2}}$ & 0.0048 & 0.0048 & 0.0048 \\
$\mathbf{N}_{\mathbf{2}}$ & 0.0041 & 0.0041 & 0.0041 \\
$\mathbf{C 1}$ & 0.7500 & 0.8159 & 0.8498 \\
$\mathbf{C 2}$ & 0.0707 & 0.0670 & 0.0554 \\
$\mathbf{C 3}$ & 0.0373 & 0.0330 & 0.0271 \\
$\mathbf{i C 4}$ & 0.0100 & 0.0100 & 0.0071 \\
$\mathbf{n C 4}$ & 0.0113 & 0.0120 & 0.0091 \\
$\mathbf{i C 5}$ & 0.0070 & 0.0055 & 0.0046 \\
$\mathbf{n C 5}$ & 0.0065 & 0.0045 & 0.0038 \\
$\mathbf{C 6}$ & 0.0101 & 0.0070 & 0.0050 \\
$\mathbf{C 7}+$ & 0.0882 & 0.0362 & 0.0292 \\
\hline
\end{tabular}

Table 2. CAPEX and OPEX variations for Scenario 2 in relation to Scenario 1.

\begin{tabular}{lccc}
\hline & J-T & TURBOEXPANSION & REFRIGERATION \\
\hline CAPEX offshore & $+6.0 \%$ & $+7.9 \%$ & $+8.0 \%$ \\
CAPEX Total & $-27.0 \%$ & $-25.6 \%$ & $-25.6 \%$ \\
OPEX offshore & $+4.1 \%$ & $+4.2 \%$ & $+4.3 \%$ \\
OPEX Total & $-11.9 \%$ & $-11.8 \%$ & $-11.7 \%$ \\
\hline
\end{tabular}

the products and the distance to the coast. For that, the economics evaluation considered 200 and 300 kilometers offshore, as well as a price variation for each product of plus or minus 10,20 , and $30 \%$. It is believed that the natural gas and the distance to shore will impact the concept selection.

\subsection{Technical evaluation}

Software Aspen HYSYS $^{\circledR}$ V8.8 performed the technical evaluation through process simulation. A process plant simulation with the main unit operations was built for each of the three systems: Scenario 2a - Joule-Thomson (J-T), 2b Turboexpansion, and $2 c-$ Refrigeration. Figure 3 presents the main processes in the plant and represents the J-T Scenario as an illustration of the process plant created in Aspen HYSYS $^{\circledR}$. For the three scenarios, the capability to produce sales gas and stabilized condensate was evaluated. Three different feed compositions were considered: poor, medium, and rich gas for the composition has a significant influence in the process ability to meet saleable product specifications. Table 1 shows the feeds in a concise version. This consideration is also due to factors such as reservoir uncertainties and possible fluid changes over the production years. The sales gas specifications are according to the
Brazilian regulations, and the main restrictions analyzed were gas methane content and hydrocarbon dew point. Complimentary, the maximum condensate Reid Vapor Pressure, 10 psia at $37.8^{\circ} \mathrm{C}$, is the parameter of interest.

In the process simulation, the Peng Robinson (PR) state equation was used for all hydrocarbon streams to calculate thermodynamic properties (Sant'Anna, 2005; Cordeiro, 2011; Chebbi et al., 2010 and Getu et. al., 2013) and, for the refrigerant fluid considered R-134a, the Redlich Kwong Soave (RKS) was used (Camporese et al., 1985).

\section{RESULTS AND DISCUSSIONS}

\subsection{Economic results and discussions}

Table 2 shows CAPEX and OPEX results in present values for Scenario 2 in relation to Scenario 1 , comparing each of the gas processes under consideration.

Results indicate significant total CAPEX and OPEX reductions for Scenario 2 when compared to Scenario 1, despite the fact that for the offshore facility itself these values are higher. The average 


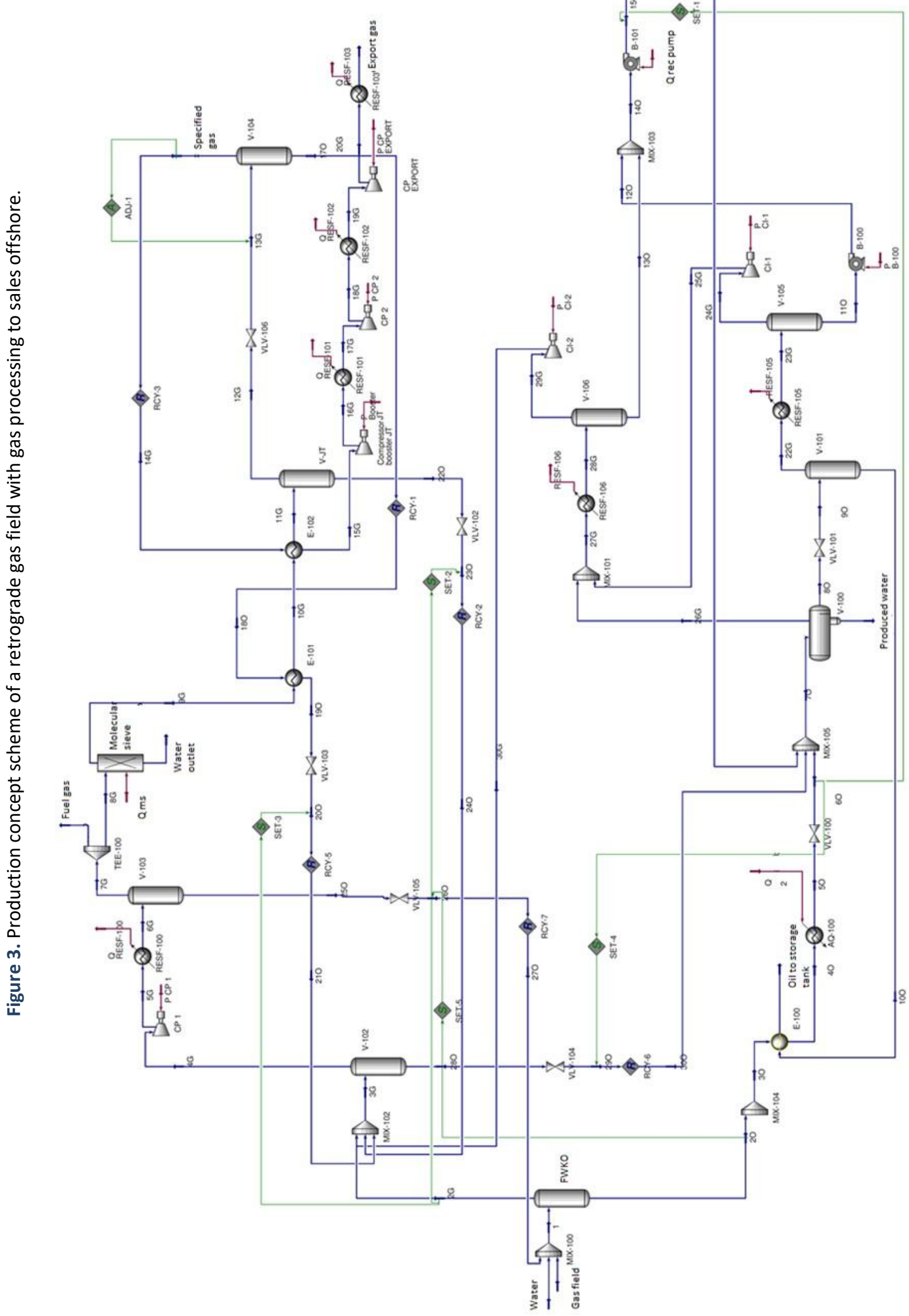


Table 3. Income, total investments, and NPV variations for Scenario 2 in relation to Scenario 1.

\begin{tabular}{lccc}
\hline & J-T & TURBOEXPANSION & REFRIGERATION \\
\hline Income & $-6.2 \%$ & $-6.4 \%$ & $-6.0 \%$ \\
Total Expenditure & $-21.6 \%$ & $-20.7 \%$ & $-20.6 \%$ \\
NPV & $+307.0 \%$ & $+283.6 \%$ & $+290.7 \%$ \\
\hline
\end{tabular}

Table 4. ROI and IRR of the evaluated options.

\begin{tabular}{ccccc}
\hline & ONSHORE & J-T & TURBOEXPANSION & REFRIGERATION \\
\hline ROI & 0.07 & 0.38 & 0.35 & 0.36 \\
IRR & $12 \%$ & $17 \%$ & $16 \%$ & $16 \%$ \\
\hline
\end{tabular}

total CAPEX reduction of approximately $26 \%$ is very significant and most of it is due to the fact that Scenario 2 does not require a significant CAPEX for the onshore gas processing facility. In this case, just a distribution terminal is needed because the gas processing is performed offshore. This reduction could have a major impact in project net present value (NPV) since it is an investment made at the beginning, before the start of the production. Therefore, this can be a great option for small companies or those that do not have much to invest at the time. Regarding the dew point processes, all three showed very similar behavior with small differences. The J-T presented the lowest CAPEX and OPEX as expected for it requires simpler equipment.

Table 3 shows results for income, total investments in present value (CAPEX and OPEX), and the net present value.

The data indicate that Scenario 1 not only demands a significantly higher investment, as data from Table 2 indicate, but also provides a slightly larger source of income. The onshore gas plant provides products with a higher price than the gas, such as LPG and gasoline, which explains the income reduction shown in Table 3 for the three processes. Again, results for the three processes were quite similar and making it hard to evaluate the small difference. When combined, income and total expenditure yield a much larger Net Present Value for Scenario 2, reaching four times the NPV observed for Scenario 1. Despite the slightly lower income, the lower CAPEX and OPEX affected more significantly the project economic results. In the global evaluation, the NPV in all three options is higher than building an onshore treatment plant for the prices considered. This occurred mainly because the field is primarily a gas producer, with very limited production of liquid fractions, which means that the income from the more valuable products (condensate, LPG and gasoline) is relatively low. Additionally, another reason for this improvement is due to Scenario 1 having a small positive NPV and, by reducing CAPEX and OPEX, a higher NPV is achieved for Scenario 2.

Despite the major growth of the NPV, the concept underlying Scenario 2 might still not be attractive economically if the NPV remained low compared to the need for capital. To verify this statement, the Return on Investments (NPV/Total Investments) and the Internal Rate of Return (IRR) indexes for each option were calculated and presented in Table 4.

The options studied in Scenario 2 are better than the option considered in Scenario 1, for it presented a higher ROI and a better IRR. Nevertheless, Scenario 2 might remain impractical considering economic variations.

The sensitivity analysis results, achieved by varying the value of the product, showed that, if the natural gas price was reduced by $10 \%$, the onshore treatment would give a negative NPV and with reductions of 20 and $30 \%$ both scenarios would give negative NPVs. When the gas price increased, the IRR and the ROI increased and improved all options significantly. In the condensate price variation, a reduction of $30 \%$ resulted in a negative NPV for Scenario 1, and a $30 \%$ increase had almost the same effect of a $10 \%$ increase in the gas price. For the LPG and gasoline price variations, the NPV results of Scenario 1 did 
Table 5. ROI and IRR for different distances to shore.

\begin{tabular}{cccccc}
\hline $\begin{array}{c}\text { DISTANCE TO } \\
\text { SHORE (KM) }\end{array}$ & ONSHORE & J-T & $\begin{array}{c}\text { TURBO- } \\
\text { EXPANSION }\end{array}$ & REFRIGERATION \\
\hline \multirow{2}{*}{100} & ROI & 0.07 & 0.38 & 0.35 & 0.36 \\
& IRR & $12 \%$ & $17 \%$ & $16 \%$ & $16 \%$ \\
\hline \multirow{2}{*}{200} & ROI & & 0.21 & 0.20 & 0.21 \\
& IRR & $11 \%$ & $14 \%$ & $14 \%$ & $14 \%$ \\
\hline \multirow{2}{*}{300} & ROI & & 0.06 & 0.05 & 0.05 \\
& IRR & $9 \%$ & $12 \%$ & $12 \%$ & $12 \%$ \\
\hline
\end{tabular}

not change significantly, since these only represented a small part of the income. As expected, the natural gas had a strong impact in the project economics. Because natural gas is the main product, a meticulous market analysis would be advisable.

The sensitivity analysis results on the distance to shore showed that, for 100 kilometers, both scenarios had positive NPVs but, for both 200 and 300 kilometers, Scenario 1 had negative NPV while Scenario 2 still had positive values of NPV (Table 5). Regarding the IRR, the values became closer and even lower than the hurdle rate with higher distances, reducing the attractiveness of the development of the considered field using either Scenario 1 or Scenario 2. From these results, it is possible to understand why many offshore fields are considered stranded gas.

It is important to emphasize that the present study considered that the project must support the onshore gas plant on its own. However, these costs could be shared with other offshore projects in the same area, if any, which would affect results significantly. This is a strategy that made the Brazilian pre-salt feasible (Vianna Filho et al., 2015) among many other projects around the world. Therefore, the advantage of Scenario 2 over Scenario 1 could even disappear if other oil or gas fields were considered to be nearby, and if these fields could be produced at the same time.

\subsection{Process simulation results and discussions}

After finding promising economic results, process simulations targeted gas and condensate separation. Figures 4 and 5 show the sales gas methane fraction and hydrocarbon dew point, respectively. Figure 6 shows the results for the condensate Reid Vapor Pressure (RVP). Dashed lines represent specification limits.

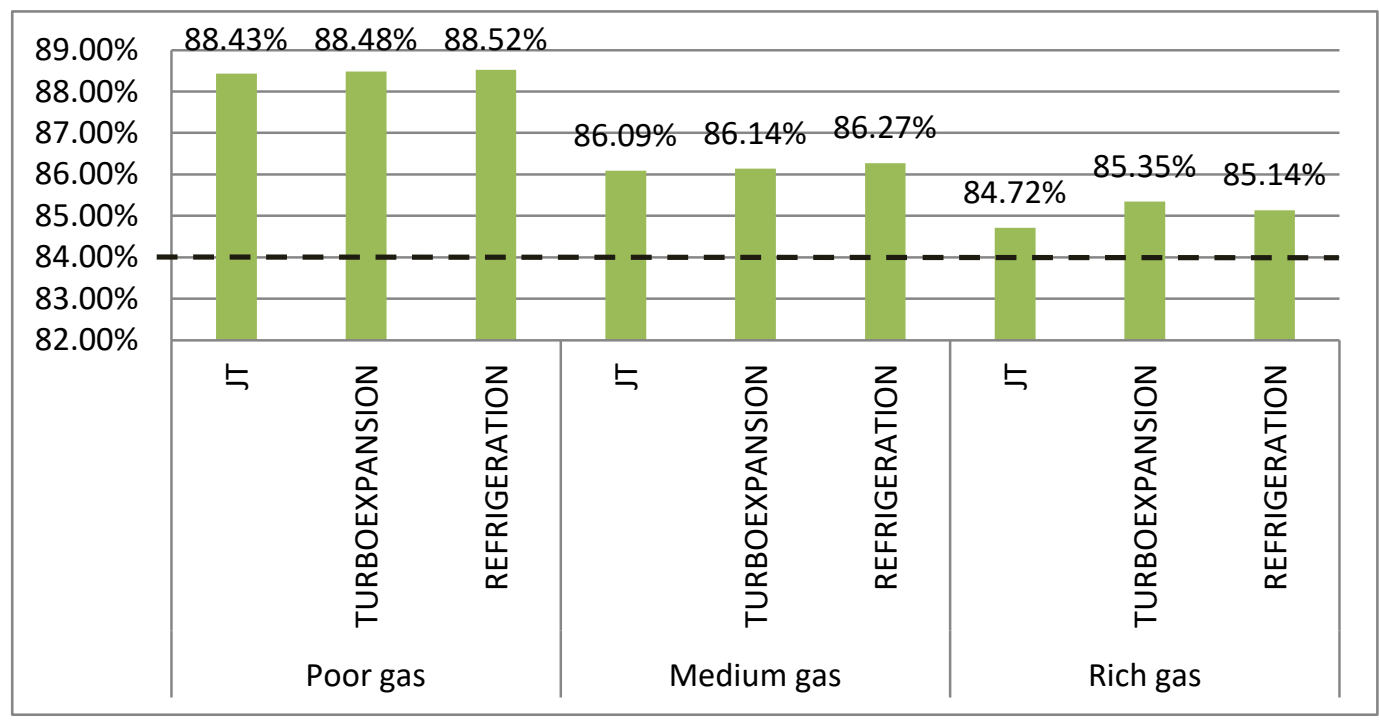

Figure 4. Methane content in the offshore treated gas. 


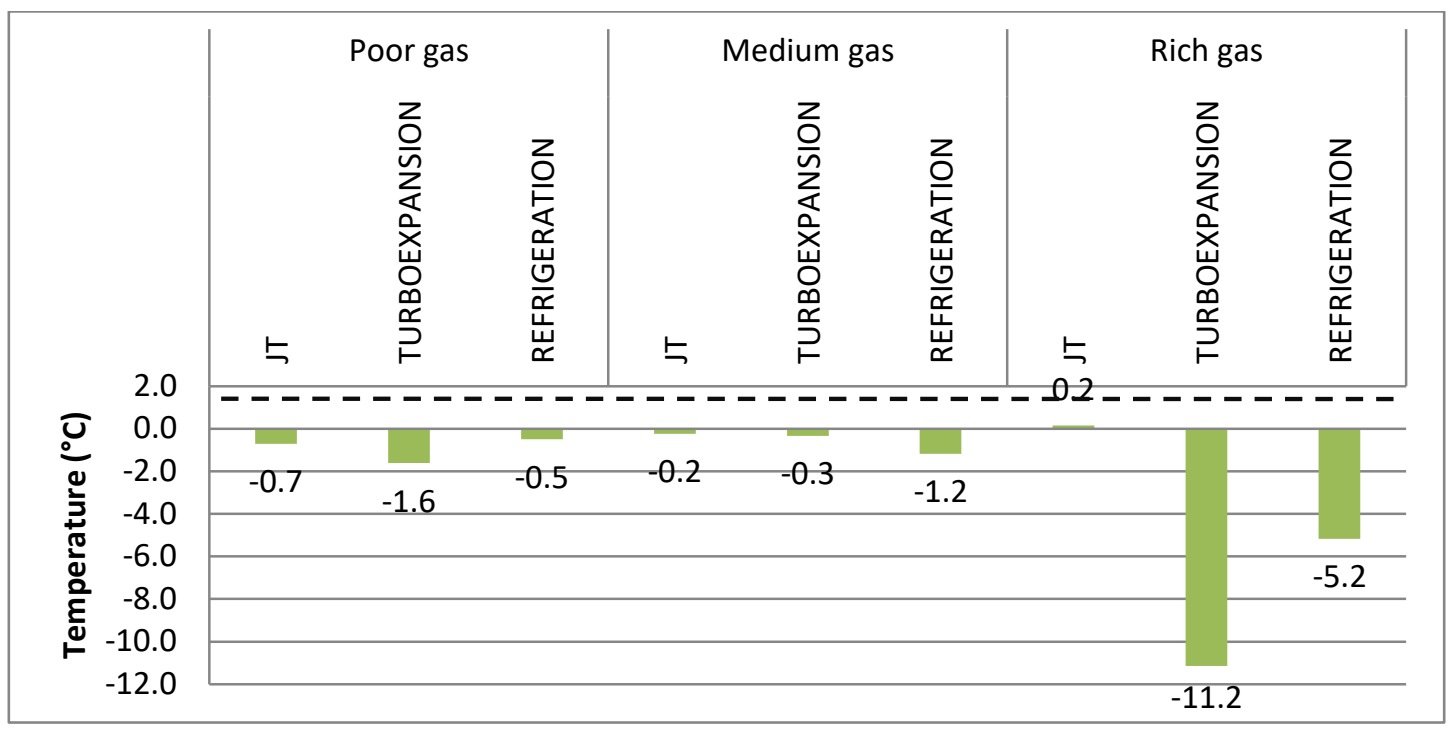

Figure 5. Hydrocarbon dew point at 4.5 MPa in the offshore treated gas.

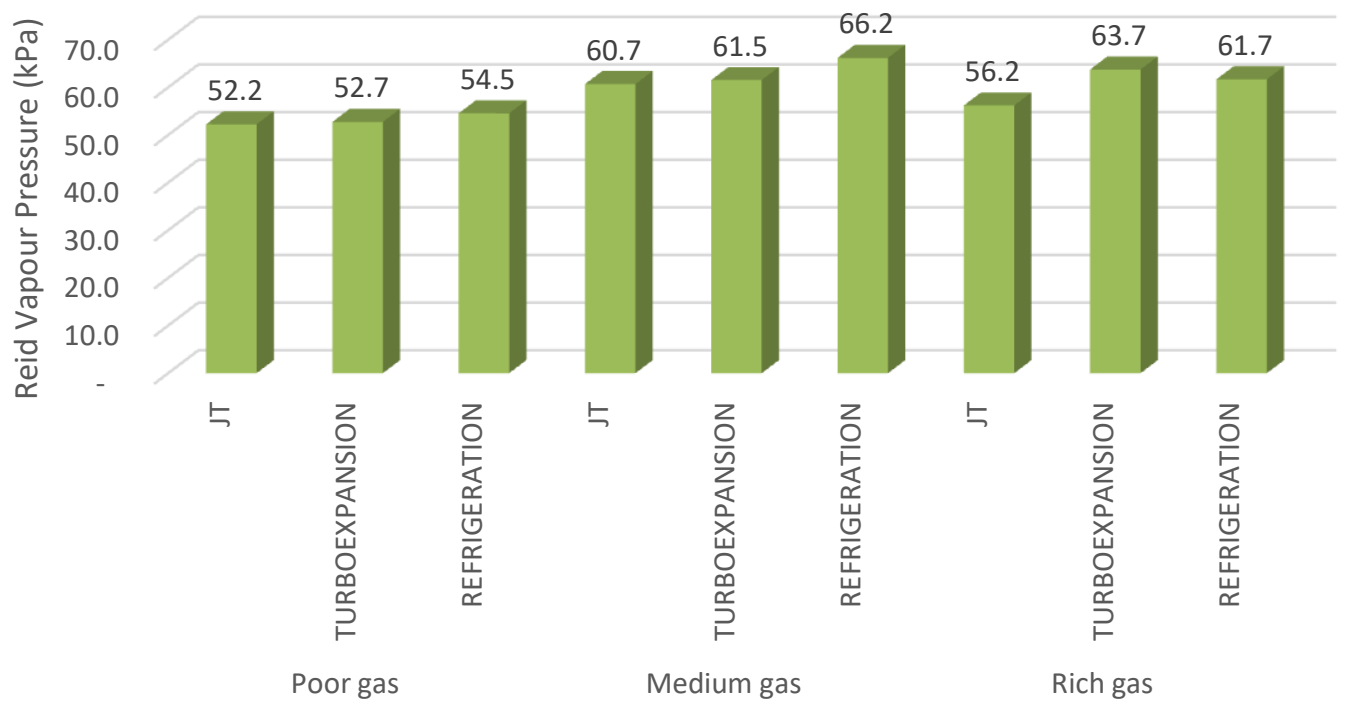

Figure 6. Condensate Reid vapor pressure (RVP).

As expected, for the poor gas, all three processes met the specifications for both gas and condensate. This happened because the feed gas composition was already very close to the sales gas composition. The methane molar percentage was very similar in each of the three adjusted gases with slight changes in the composition, hence the difference in hydrocarbon dew point and the condensate RVP. In this case, it was easier to achieve the methane content, but the hydrocarbon dew point required a little more refrigeration because of the distribution of the propane and other hydrocarbons with higher molar mass. The works of Skylogianni et al. (2015) and Louli et al. (2012) show several phase envelopes for high methane content natural gases and their hydrocarbon dew point are also high.

As expected, the "medium gas" demanded a higher pressure drop (Scenarios $2 \mathrm{a}$ and $2 \mathrm{~b}$ ) and refrigerant fluid rate (Scenario 2c), but at a lower methane content of about $86 \%$ it was possible to achieve the hydrocarbon dew point. This is also due to the hydrocarbon distribution.

For the rich gas case, the J-T process did not meet the gas specifications, unlike the turboexpansion and refrigeration processes. Even though the methane content may appear to be similar, the distribution of the gas components is very different due to recycled streams and gas 
composition. As a result, one can observe a large difference in hydrocarbon dew point temperatures resulting in a different phase envelope. Nevertheless, this case required the highest pressure drops (Scenario 2a and 2b) and refrigerant fluid (Scenario 2c) to achieve the lowest temperatures, necessary for this gas composition.

The RVP followed the methane content in the three gas compositions. With higher methane in the gas, the content of ethane, propane, and butane in the condensate is higher, resulting in a higher vapor pressure. In some cases, it is possible to treat a richer gas since more hydrocarbons with higher molar masses can be incorporated in the condensate or oil, as perceived by Orreindy et al. (2015).

It is important to consider that the sales gas offshore could reduce the flexibility for the development of other projects if present in the area. This is because when choosing not to build an onshore gas plant, all new projects will have to consider treating the gas to sales offshore or assuming a high capital investment to construct that infrastructure, if that is not possible. Therefore, it is a must to evaluate for possible new field developments close to the project under consideration to share the onshore infrastructure costs (Souza et al., 2016).

Additionally, one must study interface aspects with other areas. For example, in this concept the production depends on the specifications and the gas has to meet its properties prior to being considered for export. Whenever that is not possible, it is necessary to consider alternatives to avoid shut downs in the offshore production plant. One alternative would be to include gas injection wells, which would demand a study of the reservoir, as mentioned by Souza et al (2016).

The storage of the condensate is another important evaluation for consideration. The condensate could flash off at low pressure and high temperature, posing a safety risk and polluting environment (Rahmanian et al., 2016). Researchers must perform more detailed evaluation to define the operation conditions better.

\section{CONCLUSIONS}

From the analysis performed, the offshore sales gas concept demonstrated to improve the economics of the case study involving the retrograde gas field development project. Results showed a significant impact of natural gas price, as well as field distance to shore, in the project economics and feasibility, requiring continuous evaluations.

Process simulations indicate the possibility of using three hydrocarbon dew point systems (J-T valve, turbo expansion, and refrigeration). It also points out that there is a higher risk of not meeting the specification to sales with the use of J-T valve. In spite of that, projects using gas compositions that are well known and are poor in high molecular weight hydrocarbons, such as J-T, might be an option.

The options considered in this work may help a stranded gas project to become feasible or at least improve its economic returns. For companies with difficulties to invest, for instance, this option becomes a good solution, since it reduces capital investments.

Nevertheless, it is important to note that this is a preliminary analysis and, if considered, the authors of the present work recommend performing further studies.

In summary, the intent of this paper is to provide a wider range of possibilities for new developments during the concept selection stage. It is important to emphasize that each project is unique with many challenges and different optimized solutions.

\section{ACKNOWLEDGMENTS}

The authors would like to express appreciation to Petrobras and FAPEMIG for their support.

\section{REFERENCES}

Alcheikhamdon, Y.; Hoofar, M. Natural gas quality enhancement: A review of the conventional treatment processes, and the industrial challenges facing emerging technologies. Journal of Natural Gas Science and Engineering, v. 34, p. 689-701, 2016. https://doi.org/10.1016/i.jngse.2016.07.034 
ANP. Agência Nacional do Petróleo, Gás Natural e Biocombustíveis. Resolução $n^{\circ} 16$, de 17 jun. 2008. Diário Oficial da União, de 18 jun. 2008, Brasília.

Attanasi, E. D., Freeman, P. A. A survey of stranded gas resources and estimates of development and production costs. SPE Economics \& Management, p. 1-19, 2010. Society of Petroleum Engineers, 2010.

https://doi.org/10.2118/130089-MS

Bothamley, M. Offshore Processing Options for Oil Platforms. In: SPE Annual Technical Conference and Exhibition, Houston, 2004.

https://doi.org/10.2118/90325-MS

Camporese, R; Bigolaro, G; Rebellato, L. Calculation of thermodynamic properties of refrigerants by the Redlich-Kwong-Soave equation of state. International Journal of Refrigeration, v. 8(3), p. 147-151, 1985. https://doi.org/10.1016/0140$\underline{7007(85) 90154-9}$

Chebbi, R. et al. Optimum ethane recovery in conventional turboexpander process. Chemical Engineering Research and Design, v. 88, p. 779787, 2010.https://doi.org/10.1016/j.cherd.2009.11.003

Cordeiro, A. F. Estudo de simulação e controle de uma unidade de processamento de gás natural. 2011. Dissertação (Mestrado) - Tecnologia de Processos Químicos e Bioquímicos, Escola de Química, Universidade Federal do Rio de Janeiro, Rio de Janeiro, 2011.

Dickson, W.; Ogolo, F.; Delbianco, A. Project options to monetize stranded gas. In: Offshore Mediterranean Conference and Exhibition, 2015. Ravenna, 2015.

Getu, M.; Mahadzir, S.; Long, N. V. D.; lee, M. Techno-economic analysis of potential natural gas liquid (NGL) recovery processes under variations of feed compositions. Chemical Engineering Research and Design, v. 91(7), p. 1272-1283, 2013. https://doi.org/10.1016/i.cherd.2013.01.015

IHS MARKIT. Global NGL Market short-term outlook. IHS Energy: Midstream oil and NGL, 2017.

IHS MARKIT. Latin America NGL market short term outlook. IHS Energy: Midstream oil and NGL, 2017.
Lee, C.-J.; Song, K.; Shin, S.; Lim, Y.; Han, C. Process design for the offshore production of liquefied natural gas with nonflammable refrigerants. Industrial \& Engineering Chemistry Research, v. 54(44), p. 11106-11112, 2015. https://doi.org/10.1021/acs.iecr.5b01620

Lee, J; Eisbrenner, K.; Choi, D. Stranded gas fields development with cluster LNG technology. In: Offshore Technology Conference, p. 1-12, Houston, 2013. https://doi.org/10.4043/24205-MS

Lee, S.; Long, N. V. D.; Lee, M. Design and optimization of natural gas liquefaction and recovery processes for offshore floating liquefied natural gas plants. Industrial \& Engineering Chemistry Research, v. 51(30), p. 10021-10030, 2012. https://doi.org/10.1021/ie2029283

Lion, M.; Almeida, E. L. F.; Losekann, L. Avaliação das condições de viabilidade econômica de projetos de produção de gás natural não convencional no Brasil. Instituto de Economia, Universidade Federal do Rio de Janeiro, 2014.

Louli, V.; Pappa, G.; Boukouvalas, C.; Skouras, S.; Solbraa, E.; Kjersti, C. O.; Voutsas, E. Measurement and prediction of dew points curves of natural gas mixtures. Fluid Phase Equilibria, v. 334, p. 1-9, 2012. https://doi.org/10.1016/i.fluid.2012.07.028

Lu, W.; Yang, Y.; Liu, J.; Jia, Z.; Wang, H. Comparison of different offshore oil field development concepts. In: ISOPE Pacific/Asia Offshore Mechanics Symposium, p. 9-15, 2006. Dalian, The International Society of Offshore and Polar Engineers, 2006.

Petrobras. Preços e custos. Available at: http://www.investidorpetrobras.com.br/pt/destaq ues-operacionais/precos-e-custos>. Accessed in September 11, 2017.

Orreindy, S.; Batalla, L. F.; Superchi, G. Sales gas production challenges in an ultradeep water field. In: Offshore Technology Conference Brasil, Rio de Janeiro, 2015. https://doi.org/10.4043/26271-MS

Rahmanian, N.; Jusoh, L. S. B.; Homayoonfard, M; Nasrifar, K.; Moshfeghian, M. Simulation and optimization of a condensate stabilization process. Journal of Natural Gas Science and Engineering, v. 32, p. 453-464, 2016.

https://doi.org/10.1016/i.jngse.2016.04.028 
Rocha, I. C. C. Estudo do equilíbrio de fases de sistemas modelos e representativos de petróleo com $\mathrm{CO}_{2}$ supercrítico. 2014. Dissertação (Mestrado) - Programa de Pós-Graduação em Engenharia Industrial, Universidade Federal da Bahia, Salvador, 2014.

Sant'Anna, A. A. Simulação de processamento de gás natural em plataforma offshore. 2005. Monografia - Escola de Engenharia Química, Universidade Federal do Rio de Janeiro, Rio de Janeiro, 2005.

Skylogianni, E.; Novak, N.; Louli, V.; Pappa, G.; Boukouvalas, C.; Skouras, S.; Solbraa, E.; Voutsas, E. Measurement and prediction of dew points of six natural gases. Fluid Phase Equilibria, , v. 424, p. 8 15, 2016. https://doi.org/10.1016/i.fluid.2015.08.025

Souza, M. M. D.; Barcellos, J. F.; Andrade, A. M. T.; Ribeiro, J. Estudos de planta de processamento em FPSO para campos de gás com condensado e de óleo. Rio Oil \& Gas Expo and Conference, 2016.

Tang, B.-J.; Zhou, H.-L.; Cao, H. Selection of overseas oil and gas projects under low oil price. Journal of Petroleum Science and Engineering, v. 156, p. 160-166, 2017. https://doi.org/10.1016/i.petrol.2017.05.022
Vianna Filho, F. G.; Naveiro, J. T.; Oliveira, A. P. Developing mega projects simultaneously: The Brazilian Pre-Salt case. In: Offshore Technology Conference, Houston, 2015.

https://doi.org/10.4043/25896-MS

Yananto, H.; Girindra, Y. Conceptual design of offshore surface facilities in marginal field at heavy traffic ultra shallow water using shallow water subsea wellhead for CAPEX optimization in O-field development. In: Offshore Technology Conference Asia, 2016. Kuala Lumpur, Offshore Technology Conference, 2016. https://doi.org/10.4043/26542-MS

Yang, Q.; Yu, Q.; Zhou, H.; Yang, S. Conceptual design and techno-economic evaluation of efficient oil shale refinery processes ingratiated with oil and gas products upgradation. Energy Conversion and Management, v. 126, p. 898-908, 2016. https://doi.org/10.1016/i.enconman.2016.08.022 